\title{
Collective Autonomy: Why Groups Fight for Power and Status
}

\author{
Frank J. Kachanoff \\ Department of Psychology and Neuroscience, University of North Carolina at Chapel Hill \\ Kurt Gray \\ Department of Psychology and Neuroscience, University of North Carolina at Chapel Hill
}

\author{
Richard Koestner \\ Department of Psychology, McGill University
}

Nour Kteily

Department of Management and Organizations, Northwestern University

Michael J. A. Wohl

Department of Psychology, Carleton University

December 4th, 2021

\begin{abstract}
*This paper is currently in press at Social and Personality Psychology Compass. The contents of this version are not final and might change before publication.

Notes and Acknowledgments. This article is dedicated in loving memory to Dr. Donald M. Taylor (Professor Emeritus of Psychology at McGill University). Without Don, the ideas and collaborations behind this work would not exist. Correspondence concerning this article should be addressed to Frank J. Kachanoff, Department of Psychology and Neuroscience, University of North Carolina at Chapel Hill. Email: fkach@email.unc.edu. Kachanoff wrote the initial draft of manuscript. Gray, Koestner, Kteily and Wohl revised manuscript with Kachanoff. Order of authorship after Kachanoff is arranged in alphabetical order to denote equal contribution.
\end{abstract}




\begin{abstract}
People experience "collective autonomy restriction" when they believe other groups want to restrict their own group from freely expressing its social identity and determining its behavior. We review emerging research on the negative consequences of collective autonomy restriction for well-being, as well as its implications for group members' motivation to fight for their place within social hierarchies. We propose that group members desire two resources tied to having a favorable position within the social hierarchy - structural power (i.e., the ability to influence and resist influence from other groups) and status (being positively valued and perceived as moral by others) - because they believe that having power and status are necessary to secure their group's collective autonomy. We hypothesize that group members anticipate that other groups might restrict their group if they lack the structural power to resist outside influences, or if they are perceived as negative or immoral and worthy of restriction. We apply this power and status perspective of collective autonomy restriction to predict (1) when disempowered groups are most likely to fight against (vs. tolerate) their disadvantaged position and (2) when powerful groups are most likely to relinquish power and acknowledge their transgressions (versus defensively maintain their privileged position).

$($ Word count $=200)$
\end{abstract}

Key words: Collective Autonomy; Restriction; Power; Status; Morality; Social Identity; Intergroup Relations; Intergroup Threat; Well-Being; Hierarchy; Psychological Needs 
Running Head: Collective Autonomy, Power and Status

\section{Collective Autonomy: Why Groups Fight for Power and Status}

Social identities are critical for psychological well-being and development (Haslam et al., 2009; Oyserman, 2007; Greenaway, et al., 2016). But people do not always feel free to express the shared beliefs, values, and customs that define their groups. Disempowered groups (e.g., colonized and minority groups) have been forcefully restricted from expressing their language (Nichelle, 2018), keeping their natural hair texture (Ellis \& Jones, 2019; Rhodan, 2014), wearing their religious symbols (Alouane, 2021; BBC, 2018), or acting in accordance with their cultural values (Ray, 2019). Similarly, LGBTQ+ communities have been forcefully restricted from choosing who they marry (Ofosu, et al., 2019); prevented from disclosing their sexual orientation (Burrelli \& Feder, 2009), or prevented access to hormone therapy (Callaghan, 2007).

Experiencing restriction elicits the perception of collective autonomy restriction: perceiving that other groups want to forcefully restrict one's own group from determining its social identity and behavior (Kachanoff, Wohl, et al., 2020).

Although disempowered groups often experience real restrictions on their autonomy, powerful group members may subjectively perceive restrictions. This can occur whether or not the powerful group is restricted in reality, and, despite powerful groups enjoying a position of privilege and influence. For example, some Christians have said they feel pressured to wish others "Happy Holidays" instead of "Merry Christmas" (Boorstein \& Bailey, 2017), while some White people have argued that removing statues of White historical figures due to ties to slavery and colonialism (e.g., Canada's first Prime Minister, John A. MacDonald) restricts their expression of White identity (Race, 2021). Such perceived impingements on collective autonomy are central to populist movements in North America and Europe that oppose diversity and try to reinforce existing hierarchy (Cooper, 2016; Magistad, 2016). 
We have three goals. First, we define what collective autonomy restriction is (and is not) - differentiating it from related constructs like power and discrimination. Second, we argue (and review research suggesting) that because people feel personally restricted when they perceive collective autonomy restriction, they (i) suffer reduced psychological well-being, and (ii) engage in collective action to restore collective autonomy. We highlight how perceiving collective autonomy restriction impacts well-being and collective action uniquely from other intergroup factors previously linked to these outcomes (e.g., perceived discrimination, relative deprivation, and lacking power). Third, we propose a new theoretical perspective describing how perceiving collective autonomy restriction impacts intergroup relations: Building from general process models of threat and defense (see Jonas et al., 2014 for review) we hypothesize that group members actively seek (and defend against losing) power and status within social hierarchies to instrumentally to ensure their collective autonomy is not restricted.

\section{Collective Autonomy Restriction - Concept and Theory}

People perceive personal autonomy when they feel they can volitionally determine their own identity (i.e., their values, goals, and behaviors) without feeling pressured or manipulated by other people (Ryan \& Deci, 2017). According to self-determination theory (SDT; Ryan \& Deci, 2017) perceiving personal autonomy (versus feeling controlled) is essential for psychological well-being. Within interpersonal relationships (e.g., romantic relationships, parent-child relationships, and doctor-patient relationships) and intra-group contexts (e.g., class-rooms, organizations, and nations) people experience greater well-being when they personally feel supported to act in accord with their values and interests, versus when they feel pressured and manipulated (Deci, et al., 2006; Holding, et al., 2020; Mageau et al., 2015; Williams et al., 2006; Deci, et al., 2017; Downie, et al., 2007; Niemiec \& Ryan, 2009). 
Moving to the collective, people also have a need for their social groups to be free to determine and express their social identity without restriction from others (Kachanoff, Wohl, et al., 2020; Parker, et al., 2019). People perceive collective autonomy restrictions for different reasons that vary based on their group's social position. Disempowered groups often perceive collective autonomy restriction because their group is prevented by a more powerful group from expressing its social identity and/or is forced to conform to the worldview of the powerful group. A stark example was the residential schooling system in Canada that prevented Indigenous children from speaking their own language and dressing in their own clothes (Truth and Reconciliation Canada, 2015).

Nonintuitively, members of powerful groups can subjectively feel restricted despite their group's relative power and influence. Powerful group members feel restricted when they perceive societal pressures to change behaviors which reinforce their group's dominant position within the hierarchy, and which they grew accustomed to through being in a dominant position. For example, powerful groups might perceive that other groups are trying to control them if they are asked not to behave in ways that presume their culture is prototypical (e.g., assuming everyone celebrates Christmas), or if they are asked to remove group symbols tied to their oppression of other groups (e.g., confederate statues that Black communities perceive to symbolize anti-Black violence and restriction).

In sum, collective autonomy restriction is a subjective perception of feeling that other groups seek to control or restrict one's group. This perception may or may not reflect how one's group is actually treated and can arise among groups who are in a disempowered position (being coerced from above) and among groups who are in a powerful position (feeling pressured from below). 


\section{From Collective Autonomy Restriction to Promoting Collective Autonomy}

Instead of imposing restrictions, groups can also promote the collective autonomy of other groups. First, groups can passively support the collective autonomy of other groups simply by letting the other group coexist independently of their influence (Kachanoff, Taylor et al., 2019). Second, groups can actively affirm the importance of another group determining its identity and behavior. For instance, National Indigenous People's Day in Canada is an active celebration of the culture of Indigenous peoples. Third, groups may suggest new ways of behaving to another group by explaining its value, taking the other group's perspective, and respecting the other group's choice to ultimately determine what they do (versus imposing the new behavior forcefully; Kachanoff et al., 2017; Legault et al., 2011).

Within interpersonal contexts (focused on by SDT) autonomy support most often involves autonomously providing advice or directives, and the passive form of support would not even be considered autonomy support but independence (Ryan \& Deci, 2017). However, intergroup contexts differ from interpersonal contexts. Within interpersonal relationships (e.g., friendships, parent-child relationships) both parties likely assume they have each other's best interests at heart. But intergroup contexts are commonly less trusting and more competitive than interpersonal relationships (Tajfel \& Turner, 1979). Thus, groups may perceive 'advice' from others as inappropriate or paternalistic (even if suggested in an autonomy supportive fashion). For example, Iyengar and Lepper (1999) found that universally, children did not react positively to children from a salient outgroup (a different classroom) making decisions for them.

An important direction for future research is to examine whether depending on the intergroup context, different forms of collective autonomy support might be appropriate. Often groups might expect other groups to passively respect their own way of doing things (e.g., two 
independent nations). However, within contexts where one group already feels restricted by another group, explicit affirmations of their autonomy might help to mitigate this threat. For example, groups who have been victimized by a transgressor group respond more effectively to an apology delivered by the transgressor group when the transgressor explicitly acknowledges the importance of the victimized group having autonomy to choose whether to accept the apology (Kachanoff, Caouette et al., 2017). Finally, in certain contexts, groups might feel justified to make suggestions to other groups for how to behave (e.g., receiving group members explaining their norms to immigrating group members, or groups voicing concerns about an outgroup behavior they perceive to be harmful to others). However, in terms of the latter form of support, the group providing a suggestion for how to behave (and the group receiving it) might differ on whether they feel this is appropriate (Verkuyten, Adelman, et al., 2020; Verkuyten, Yogeeswaran et al., 2020).

\section{Defining What Collective Autonomy Restriction Is (and Is Not)}

Collective autonomy restriction is distinct from other intergroup perceptions, including the perception of lacking power. As we have described (and will provide evidence for), both disempowered and powerful groups can perceive their collective autonomy is being restricted. Further, members of groups lacking structural power to resist outside influences, can still perceive collective autonomy (rather than restriction) so long as other groups do not try to control them. For example, 'intergroup tolerance' refers to how groups with power might allow other groups to express their culture (even if they disapprove of their culture). When groups are tolerated, they may feel they have collective autonomy because no outgroup is restricting them. However, tolerated groups still feel powerless because they know other groups have the capacity to restrict them if they wanted (Bagci, et al., 2020; Cvetkovska et al., 2020). 
Consistent with our theorizing, autonomy and power are also separable at the individual level. SDT-based research suggests that people with relatively low power (e.g., children, students, patients) can feel either autonomy supported (or controlled) by people with power over them (e.g., parents, teachers, doctors; Ryan \& Deci, 2017). Moreover, even people with power can feel pressured by those with less power (e.g., teachers feeling pressured by students; Pelletier et al., 2002).

Collective autonomy restriction is also separable from the discrimination, humiliation, exploitation or feeling of devaluation that groups sometimes experience. Certainly, restrictions of autonomy can go hand-in-hand with other forms of subjugation: Within residential schools, Indigenous children were forcefully prevented from expressing their culture, but they were also devalued, humiliated, and mentally and physically abused (Truth and Reconciliation Canada, 2015). However, there are instances in which groups are subjected to restrictions by a group without being explicitly derogated.

Theories of intergroup toleration differentiate between attitudes towards the cultural practices of another group, and attitudes towards people belonging to another group (Verkuyten, Adelman, et al., 2021). People may feel negatively towards a group's cultural practices and impose restrictions without devaluing the group as whole; or conversely people may derogate members of another group without trying to restrict them. Groups sometimes paternalistically impose their values on other groups for ostensibly benevolent reasons (Bruneau et al., 2019), or argue that banning a group's cultural practice will protect (versus undermine) the basic rights of members within the group (O’Neill, 1999). For example, some people support banning nonmedical Jewish male circumcision out of concern for Jewish children (Munzer, 2015). Similar parallels can be drawn within interpersonal contexts between restrictions placed on individuals 
out of cruelty (e.g., an abusive parent), versus restrictions motivated by knowing "what is best" (e.g., a parent imposing a strict bedtime). At the intergroup level, 'knowing what is best' forms of restriction may be rooted in beliefs of superiority among the restricting group (and can be destructive by stifling behaviors that the restricted group see as core to their identity). Still, this form of restriction likely differs from restriction motivated purely by prejudice towards the restricted group (Verkuyten, Adelman, et al., 2020).

Lastly, groups may have their cultural expression explicitly celebrated, while still being exploited in other ways. Indigenous scholars in Canada have critiqued ongoing decolonization efforts as being a 'metaphorical' surface level embrace of Indigenous culture without efforts to address other systemic inequities that exist between the non-Indigenous and Indigenous Canadians (Tuck \& Yang, 2012).

In sum, while the concept of collective autonomy answers the question "are we free without restriction?", other intergroup concepts answer questions like "are we strong?", “are we valued?" and "are we treated fairly?" While often experienced hand-in-hand, these perceptions are still distinguishable. Next, we consider the unique consequences of collective autonomy restriction for group members that emerge beyond these other intergroup perceptions.

\section{The Consequences of Collective Autonomy Restriction}

Mounting research suggests that perceiving collective autonomy restriction is consequential for (i) whether group members experience psychological well-being, as well as, (ii) how they direct their behavior within intergroup contexts.

\section{Collective Autonomy Restriction is Detrimental to Psychological Well-Being.}

Research rooted in the social identity approach (Tajfel \& Turner, 1979; Hornsey, 2008) suggests that how people identify with and perceive their social groups is consequential for 
psychological well-being (Haslam et al., 2009). The social identity approach argues that people derive their sense of self (e.g., their goals and values; Oyserman, 2007) partly from their social identity. Having a collective sense of "we" also provides people with psychological resources to navigate life challenges (Greenaway et al., 2015; Haslam et al., 2014). Because people tie their personal identity to their social groups, and experience a sense of "we", they are personally impacted by what happens to their group (see Leigh \& Melwani, 2019 for review). Initial research showed that people's self-esteem is tied to whether they feel that others value their group (e.g., Luhtanen \& Crocker, 1992). Subsequent research suggested that identifying with social groups fulfills other essential needs for well-being (e.g., efficacy and agency, relatedness, and meaningfulness) and that negative intergroup experiences (like feeling others do not tolerate their group) compromise these needs (Bagci et al., 2020; Cvetkovska, et al., 2020).

Studying the psychology of collective autonomy restriction reveals a novel pathway through which intergroup perceptions impact psychological needs and well-being. Because people feel interconnected to their social groups, they likely feel personally restricted when they perceive their social group to be restricted. As Nelson Mandela said of the Apartheid regime in South Africa: "Freedom is indivisible; the chains on any one of my people were the chains on all of them, the chains on all of my people were the chains on me” (1995, p.624). Providing evidence for the link between collective autonomy restriction and reduced personal autonomy, one experiment found that participants personally felt controlled if they were prevented (versus permitted) by a powerful outgroup from expressing their social identity (i.e., controlling a videogame character that reflects their group identity; Kachanoff, Taylor et al., 2019).

Feeling personally restricted because of group restrictions is detrimental to well-being. Perceiving collective autonomy restriction is associated with lower life satisfaction and self- 
esteem, as well as greater depression and negative affect (Kachanoff et al., 2019), and this relation is mediated by reduced personal autonomy. The link between collective autonomy restriction, personal autonomy, and psychological well-being is robust when tested with crosssectional, longitudinal, and experimental research designs (Kachanoff et al., 2019), and has been replicated independently by different research groups across several different countries using different measurement scales (Parker et al., 2019). Finally, collective autonomy restriction is negatively associated with psychological well-being among disempowered communities that have chronically been restricted by other social groups including the LGBTQ+ community (Kachanoff, Cooligan et al., 2020) and Black communities in Canada and the United States (Holding \& Koestner, 2021).

Importantly, collective autonomy restriction is uniquely associated with personal autonomy and well-being even when statistically accounting for other group perceptions associated with well-being (Kachanoff, Taylor, et al., 2019) like group agency, efficacy and control (e.g., Greenaway et al., 2015, 2016), and perceptions that others like and value one's group (e.g., Branscombe et al., 1999).

Providing experimental evidence for the uniqueness of collective autonomy restriction from group power, one study (Kachanoff, Taylor et al., 2019) found that groups who were told that a high-power group could change their culture, but ultimately were free to express their culture, did not differ in their perceptions of collective autonomy or personal autonomy relative to group members who were never vulnerable to restriction. It was only when the group had its culture restricted by a powerful group that people perceived collective autonomy restriction and felt less personal autonomy. There is also experimental evidence suggesting the uniqueness of collective autonomy restriction from discrimination. For example, having LGBTQ+ individuals 
think about how their LGBTQ+ community has its collective autonomy restricted (versus is free to determine its identity and behavior) robustly increased their perceptions of collective autonomy restriction (Kachanoff, Cooligan et al., 2020). But the manipulation did not reliably change whether LGBTQ+ individuals felt discriminated against as a group, or felt personally supported to express their identity within their interpersonal relationships. In turn, thinking about collective autonomy restriction (versus support) uniquely reduced personal autonomy and wellbeing accounting for anti-LGBTQ+ discrimination (Ryan et al., 2017) and feeling supported interpersonally (Legate et al., 2012, 2017; Al-Khouja et al., 2021a).

\section{Groups Collectively Challenge Restrictions to their Autonomy}

Research suggests that groups act collectively to improve their group's position when they feel unjustly treated (Van Zomeren et al., 2008). Core sources of perceived injustice previously considered include feeling that one's group is unfairly deprived scarce resources relative to others (Walker \& Smith, 2002) or is subjected to discrimination (Mummendey et al., 1999). Studying the psychology of collective autonomy restriction introduces another important pathway to collective action.

Since people have a psychological need for collective autonomy, they are likely to challenge restrictions (and the outgroups who they feel impose them). These collective responses to restriction impact whether social hierarchies remain stable (Sidanius, et al., 1994). Members of disempowered groups act to gain structural power (and change the existing hierarchy) so they can use power to resist restriction. However, powerful groups also believe they can use power to double-down on the restrictions they perceive against their group. Thus, they might act to maintain or extenuate existing social hierarchies to keep or gain power. 
Supporting these predictions, the more Black Americans (a disempowered group) perceived collective autonomy restriction, the more they wanted to challenge the current social system by supporting movements like Black Lives Matter (Kachanoff, Kteily et al., 2020). Moreover, Black Americans were less likely to justify the existing social system to the extent they felt restricted. Importantly, these effects were robust when accounting for other factors that motivate collective action, such as perceived discrimination against one's group, or being relatively deprived (e.g., lacking jobs, housing, money; Mummendey, et al., 1999; Van Zomeren, et al., 2012; Walker \& Smith, 2002). Disempowered groups' collective response to restriction goes beyond the general tendency for groups to engage in collective action when they feel unjustly treated (Van Zomeren et al., 2008). In one experiment (Kachanoff, Kteily et al., 2020), when a powerful outgroup restricted (vs. allowed) the participant's group from expressing its culture, participants expressed more hostile emotions towards the powerful outgroup (a driver of collective action; Van Zomeren et al., 2009), and participants were more likely to retaliate against the outgroup (e.g., by sending them plastic beads which represented explosives). These effects were robust both when the participants' group was treated unjustly by the high-power outgroup in other ways (i.e., by being forced to do all the work on a boring task) or if they were treated fairly by the powerful group. These findings suggest that experiencing restriction drives collective action in disempowered groups independently of whether groups experience other forms of oppression.

Disempowered groups' response to collective autonomy restriction disrupts existing hierarchy. In contrast, powerful groups try to maintain hierarchy when they feel restricted. In a representative study (Kachanoff, Kteily, et al., 2020) of White Americans (a powerful group), $42 \%$ percent of White respondents perceived that other groups wanted to restrict White 
Americans. Although perceptions of collective autonomy restriction were significantly higher among a representative sample of Black Americans collected in parallel (given their lived experiences of oppression), this study shows that perceptions of restriction are not uncommon among powerful groups. Perceiving restriction was positively associated with White Americans' support for collective action to look out for the interests of White Americans, countermovements to social justice like "White Lives Matter", and their belief in worldviews like the Protestant Work Ethic that legitimize existing hierarchy.

\section{A Power and Status 'Threat and Defense' Perspective of Collective Autonomy Restriction}

We propose a power and status 'threat and defense' perspective of collective autonomy restriction (Table 1) to predict how perceiving one's collective autonomy to be threatened (versus secure) leads to hierarchy challenging versus hierarchy enhancing behaviors among disempowered and powerful groups. We suggest that people assume two core resources tied to their group's position within the social hierarchy—-their group's power (i.e., their potential to influence and resist influence; Pratto, 2016) and status (i.e., the positivity and moral value of their group identity; Cheng et al., 2013) — are instrumental for their group to maintain its autonomy. People likely believe their groups are most vulnerable to restriction when their group (i) lacks structural power to resist outside influences and/or (ii) when other groups view their group's identity to be negative and/or immoral and thus worthy of restriction. As a consequence, we hypothesize that perceiving collective autonomy restriction leads disempowered groups to become more motivated to gain power and status, and powerful groups to become more defensive about losing power and status.

Having a favorable position within the social hierarchy often affords groups greater power and/or status (e.g., Cheng et al., 2013). Groups have power when they have the resources 
to exert influence on other groups and to resist the influence of other groups (Lammers, et al., 2016; Pratto, 2016). Separately, a group's status is based on how they are perceived by others: For example, status can come from being positively valued by other groups (Tajfel \& Turner, 1979) or by being perceived as moral (Shnabel \& Nadler, 2015).

Group members experience greater well-being when they feel their group has agency and control (i.e., power) within its environment (e.g., Greenaway et al., 2015, 2016; Bagci et al., 2020; Cvetkovska et al., 2020) and when they feel that their groups are regarded as good or moral by others (i.e., high in status; Branscombe et al., 1999; Schmitt et al., 2014). Groups also use power and status to avoid being exploited or harmed by other groups (e.g., by defending against violence or securing further resources). Thus, it is not surprising that several models of intergroup threat focus on power or status: Shnabel and Nadler's (2015) needs-based model of reconciliation differentiates between threats to agency (power) and morality, while integrated threat theory (Stephan et al., 2009) differentiates between realistic threats to a group's resources and power versus symbolic threats to a group's identity (including its positive and moral value). We propose that beyond the other benefits of power and status, people view power and status as being fundamental resources for their group to maintain collective autonomy.

Group members likely feel more vulnerable to restriction when they believe their group lacks the structural power and resources to resist outside influences. Research shows how groups (and individuals) desire power not only to exert influence onto others but to remain free from the influence of others (Lammers, et al., 2016; Pratto, 2016). For example, disempowered group members have a greater need to increase their group's power when another high-power group has the ability to influence their group's cultural expression and uses (versus does not use) its influence to restrict their culture (Kachanoff, Kteily et al., 2020). 
Group members also likely believe that other groups will be more willing to impose restrictions on them when they view their group as negative and inferior, or as immoral and harmful. As we reviewed, groups sometimes paternalistically try to change the cultural practices of other groups because they view those practices as inferior compared to their own (Bruneau et al., 2019). Groups also restrict cultural practices they consider immoral (see, Verkuyten, Adelman, et al., 2020, 2021). For example, Adelman and colleagues (2021) found that national majority members in Europe supported restricting the practices of Muslim minorities when they perceived the harm of Muslim practices to outweigh the value of supporting Muslim liberties (also see Hirsch et al., 2019). Moral arguments have also been used to call for the removal of monuments tied to the legacy of powerful groups - such as the Cecil Rhodes statue at Oxford -as the statue is not only viewed as a symbol of British pride and accomplishment, but of White supremacist and colonial ideas (Timalsina, 2021).

If people believe that power and status are important resources for maintaining collective autonomy, then disempowered and powerful groups should be more motivated to gain (or defend against losing) power and status when they feel their collective autonomy is threatened (vs. secure). Our perspective is rooted in general process models of threat and defense (see Jonas et al., 2014 for review) which suggest that individuals (and groups) engage in avoidant or approach behaviors to secure core psychological needs they perceive to be threatened. We predict that disempowered groups presently lacking status and power might tolerate their disadvantaged position in the hierarchy more when they feel their collective autonomy is secure (vs. threatened) - this is because they feel less urgency to acquire power/status to protect their collective autonomy. Conversely, powerful groups might tolerate giving up some of their power, and acknowledge their group's moral transgressions more when they believe their collective 
Running Head: Collective Autonomy, Power and Status

autonomy would remain secure. We expand these predictions (and avenues for how they may be tested in future research) for disempowered and powerful groups in turn (see Table 1 for summary).

Table 1. A power and status "threat and defense" perspective of collective autonomy restriction

\begin{tabular}{lll}
\hline & $\begin{array}{l}\text { Collective Autonomy } \\
\text { Perceived as Secure }\end{array}$ & $\begin{array}{l}\text { Collective Autonomy } \\
\text { Perceived to be Threatened }\end{array}$ \\
\hline Disempowered Group & $\begin{array}{l}\text { More tolerance for lacking } \\
\text { structural power and status }\end{array}$ & $\begin{array}{l}\text { More mobilization to gain } \\
\text { power and status }\end{array}$ \\
Powerful Group & $\begin{array}{l}\text { More openness to } \\
\text { relinquishing power / } \\
\text { acknowledging intergroup } \\
\text { transgressions perpetrated } \\
\text { against other groups. }\end{array}$ & $\begin{array}{l}\text { More defensiveness against } \\
\text { relinquishing power } / \\
\text { acknowledging intergroup } \\
\text { transgressions perpetrated } \\
\text { against other groups. }\end{array}$ \\
\hline
\end{tabular}

Disempowered Groups. Disempowered groups experience restriction when powerful groups use their power to impose restrictions (Pratto, 2016; Kachanoff, Kteily, et al., 2020) and/or regard their social identity as negative, inferior, or immoral and worthy of restriction (Verkuyten, Adelman, et al., 2020, 2021; Bruneau et al., 2019; Ray, 2019). Thus, disempowered groups who are forcefully restricted (versus permitted) to express their culture might mobilize strategically to gain power which they can use to ward off the unwanted influence of powerful groups (Kachanoff, Kteily, et al., 2020).

Past research suggests that experiencing restriction (versus freely expressing social identity) motivates disempowered groups to fight for power (Kachanoff, Kteily, et al., 2020). But future research should test whether disempowered groups are more willing to tolerate lacking structural power when other groups explicitly affirm (secure) their collective autonomy. If part of the reason group members desire structural power and status is to secure their group's collective 
autonomy, then disadvantaged groups who feel secure about their group's collective autonomy might no longer see gaining power and status as instrumental to securing their autonomy (Jonas et al., 2014). Explicit affirmation of the disempowered group's culture (e.g., Black History Month and National Indigenous People's Day) might make disempowered group members feel more secure about their collective autonomy and have important benefits for their well-being. But such initiatives might also decrease the urgency of disempowered groups to challenge their disadvantaged position within the hierarchy.

Of course, experiencing other forms of oppression like violence or exploitation also uniquely drive disempowered groups' collective action motives independently of whether they feel secure or threatened about their autonomy (Kachanoff, Kteily, et al., 2020). Still, understanding how affirming the disempowered group's collective autonomy influences their relative drive for power and status (independent of the other injustices they experience) can have important policy implications. If affirming the disempowered group's collective autonomy reduces their urgency to fight for power, then structural power inequities could be reinforced when powerful groups affirm the cultural expression of disempowered groups without also relinquishing structural power. For instance, Tuck and Yang (2012) caution that merely affirming the importance of Indigenous culture will do little to reduce structural inequities between Indigenous and non-Indigenous peoples, if Indigenous peoples are not also given back their land and greater governance. To prevent the maintenance of existing hierarchies it may be essential for initiatives to affirm the disempowered group's collective autonomy to go hand-inhand with concrete efforts to return power (land and governance) and status (access to highprestige positions) to these groups. 
Beyond the collective power and status seeking behaviors emphasized in our framework, disempowered group members who perceive their group to be restricted may also individually change their behavior to satisfy their psychological need for personal autonomy that is stifled through perceiving group restriction. For instance, Al-Khouja and colleagues (2021b) found that women who feel collectively oppressed become more motivated to personally engage in selfexpression as a means of satisfying their need for personal autonomy. Future research should investigate what factors determine whether disempowered group members react to collective autonomy restriction collectively by trying to gain power and status, versus individually engaging in actions to satisfy their personal need for autonomy (e.g., self-expression).

Powerful Groups. Members of powerful groups may fear that social changes which lower their group's position within the hierarchy, or, which call into question their moral status, could result in a loss of collective autonomy. When powerful group members think about intergroup relations as a zero-sum game, they perceive gains in power for disempowered groups as a loss in power for their own group (Eibach \& Keegan, 2006). For example, some majority group members perceive demographic shifts (i.e., the 'majority-minority shift' which projects that racial minorities will outnumber Whites in the US within three decades) as a threat to White Americans' societal position (Craig \& Richeson, 2014).

Some powerful group members anticipate that power shifts will disrupt their group's freedom to express its culture in the ways they had grown accustomed to (which often involves an implicit assumption that their culture is the standard or prototypical culture in society). For example, Danbold and Huo (2014) found that White Americans are threatened by the majorityminority shift because they anticipate that White identity will no longer define what it means to be prototypically American. Relatedly, Stefaniak and Wohl (2021) found that the majority- 
minority shift can evoke a concern in White individuals living in the US, Canada, and the UK that their social identity and culture will disappear. Finally, Zárate and colleagues (2012) find that people are most negative to incoming immigrants if they feel their arrival will force their own group to have to change its culture.

In addition to power threats, powerful groups perceive threats to their moral status because of their group's transgressions to disempowered groups (Shnabel \& Nadler, 2015; Peetz, et al., 2010). In the context of American race relations, White Americans may feel as though they are perceived as the primary perpetrators and beneficiaries of racism (Unzueta \& Lowery, 2008). Powerful group members perceive collective autonomy restriction as one consequence of losing their moral status. For example, Takahashi and Jefferson (2021) found that White Americans felt restricted in what they could say in conversations about race because they feared their views would be perceived as racist. Other work suggests that critical messages about structural racism (e.g., "White Silence is Violence") evoke perceptions of collective autonomy restriction in White Americans who interpret these messages to imply that all White Americans (including those who are indifferent about race issues) are racist in character (Kachanoff, et al., 2021).

We apply our power and status perspective of collective autonomy restriction to predict when powerful group members will be most defensive about relinquishing power or reconciling with their transgressions. If part of the reason why powerful groups defend their power and status is to protect their collective autonomy, then powerful groups should be more defensive about relinquishing power or acknowledging their transgressions when they feel their collective autonomy could be jeopardized. Supporting this hypothesis, White Americans who felt that they are not free to express themselves in conversations about race (out of fear of being judged racist) were more likely to abandon these conversations (Takashi \& Jefferson, 2021). Similarly, White 
Americans who felt collective autonomy restriction in response to critical anti-racist messages were more likely to oppose those messages (Kachanoff, et al., 2021) and deny that Black Americans (versus White Americans) face greater discrimination in the United States.

Importantly we can apply our model to guide intervention strategies to reduce powerful groups' reticence to giving up power or to acknowledge ingroup transgressions. One strategy could be to affirm their sense of collective autonomy. If powerful groups view power and status as vital resources to defend against the threat of collective autonomy restriction, then they may be more willing to relinquish these resources when they are made to feel secure about their collective autonomy. Providing support for this hypothesis, SimanTov-Nachlieli and colleagues (2016) found that Israeli Jews who had their group self-determination affirmed became more willing to relinquish power to Palestinians (SimanTov-Nachlieli et al., 2016).

Relatedly, Legault and colleagues (2011) found that non-Black individuals were more receptive to anti-racism campaigns that were delivered in an autonomy supportive fashion (i.e., by explaining why prejudice reduction is important and worthwhile) versus a controlling fashion (i.e., by warning that those who are prejudiced will be excluded and ostracized). Similarly, police officers (a relatively powerful group) were more supportive of diversity enhancing behaviors when they felt that within their police force, they personally had their autonomy supported in adopting such values (versus were coerced into doing so; Al-Khouja, Graham, et al., 2020). Although this work examined the impact of powerful group members personally feeling autonomy-supported as individuals, it is likely that these interventions also impacted people's perceptions of whether their entire group had collective autonomy in doing so (i.e., can nonBlack people choose whether to engage in prejudice reduction or can police officers choose whether to engage in diversity enhancing behaviors). A direction for future work will be to 
examine whether explicitly supporting the collective autonomy of an entire high-power group to engage in equality enhancing behaviors can motivate group members within to do so.

A related but separate intervention strategy may be to guide powerful group members to reframe the relinquishing of (some) power and the acknowledgement of moral transgressions as being congruent (rather than in conflict) with maintaining collective autonomy. Powerful group members could be shown that engaging in hierarchy attenuating behaviors or acknowledging their group's past transgressions is a means to social identity affirmation. For example, Helms' (1995) theory of White racial identity development argues that pro-social outcomes may stem from finding ways for White Americans to express White identity in a way that aligns with racial equity (e.g., celebrating White historical figures who fought alongside Black civil rights leaders; also see Tatum, 1992). Such intervention approaches may help powerful group members feel that they can relinquish power and repair their group's transgressions without losing their ability to express their social identity.

\section{Conclusion}

Studying the psychology of collective autonomy restriction—-people's subjective perception that other groups want to forcefully restrict their group's social identity and behavior- provides new insight into how social identity impacts well-being and collective action. While this area of research is still nascent, initial evidence suggests that groups seek power and status (tied to their position within a social hierarchy) partly to defend against collective autonomy restrictions. Thus, perceptions of collective autonomy restriction are an important predictor for when disempowered and powerful groups will either challenge or reinforce existing social hierarchies. Continued research on collective autonomy restriction may provide fruitful avenues for developing policies and interventions to reduce existing structural inequities. 
Running Head: Collective Autonomy, Power and Status

\section{References}

Adelman, L., Verkuyten, M., \& Yogeeswaran, K. (2021). Moralization and moral trade-offs explain (in) tolerance of Muslim minority behaviours. European Journal of Social Psychology. DOI: 10.1002/ejsp.2792

Al-Khouja, M., Weinstein, N., \& Legate, N. (2021a). Long-term mental health correlates of social supportive relationships in a lesbian, gay, and bisexual sample. Psychology \& Sexuality, 12, 180-192. 10.1080/19419899.2019.1687580

Al-Khouja, M., Weinstein, N., \& Legate, N. (2021b). Motivated to Express: Salience of Oppression Toward Other Women Encourages Women’s Self-Expression. Journal of Social and Political Psychology, 9, 290-305. Doi: 10.5964/jspp.6757

Al-Khouja, M., Graham, L., Weinstein, N., \& Zheng, Y. (2020). How autonomy support and ethical value alignment influences attitudes towards diversity in English police. Journal of Moral Education, 49(3), 365-380. 10.1080/03057240.2019.1697867

Alouane, R.-S. (2021). Where face masks are required but Burqas are banned. ForeignPolicy.Com. https://foreignpolicy.com/2021/03/10/switzerland-europe-burqa-ban referendum-coronavirus-face-masks-egerkinger-komitee/

Bagci, S. C., Verkuyten, M., Koc, Y., Turnuklu, A., Piyale, Z. E., \& Bekmezci, E. (2020). Being tolerated and being discriminated against: Links to psychological well-being through threatened social identity needs. European Journal of Social Psychology, 50, 1463-1477. DOI: 10.1002/ejsp.2699

BBC. (2018). The Islamic Veil Across Europe. BBC. https://www.bbc.com/news/world-europe13038095 
Running Head: Collective Autonomy, Power and Status

Boorstein, M., \& Pulliam Bailey, S. (2017, December 22). Hate saying "Merry Christmas" now? Everyone has Trump on the brain. The Washington Post. Retrieved from https://www.washingtonpost.com/news/acts-of-faith/wp/2017/12/22/hate-saying- merrychristmas-now-everyone-has-trump-on-the-brain/?utm_term=.f4522b98ae9a

Branscombe, N. R., Schmitt, M. T., \& Harvey, R. D. (1999). Perceiving pervasive discrimination among African Americans: Implications for group identification and well- being. Journal of personality and social psychology, 77, 135-149. DOI: 10.1037/0022- 3514.77.1.135

Bruneau, E., Szekeres, H., Kteily, N., Tropp, L. R., \& Kende, A. (2019). Beyond dislike: Blatant dehumanization predicts teacher discrimination. Group Processes \& Intergroup Relations. DOI: $10.1177 / 1368430219845462$

Burrelli, D. F., \& Feder, J. (2009). Homosexuals and the U.S. Military: Current Issues [Congressional Research Service Report for Congress]. Congressional Research Service. Callaghan, T.D. (2007). Contra/diction: How catholic doublespeak in Canadian Catholic secondary schools furthers homophobia. The Canadian On-Line Journal of Queer Studies in Education, 3, 1-22.

Cheng, J. T., Tracy, J. L., Foulsham, T., Kingstone, A., \& Henrich, J. (2013). Two ways to the top: Evidence that dominance and prestige are distinct yet viable avenues to social rank and influence. Journal of Personality and Social Psychology, 104, 103-125. Doi: $10.1037 / \mathrm{a} 0030398$

Cooper, W. (2016). The scared white people who love Donald Trump. Vice. Retrieved from https://www.vice.com/en_us/article/wdbqwb/the-alt-rights-fear-of-a-black-planet 
Running Head: Collective Autonomy, Power and Status

Craig, M. A., \& Richeson, J. A. (2014). More diverse yet less tolerant? How the increasingly diverse racial landscape affects white Americans' racial attitudes. Personality and Social Psychology Bulletin, 40, 750-761. DOI: 10.1177/0146167214524993

Cvetkovska, S., Verkuyten, M., \& Adelman, L. (2020). Being tolerated and minority well-being: The role of group identifications. International Journal of Intercultural Relations, 74, 161-173. DOI: 10.1016/j.ijintrel.2019.10.010

Danbold, F., \& Huo, Y. J. (2014). No Longer “All-American”? Whites' defensive reactions to their numerical decline. Social Psychological and Personality Science,1-9DOI: 1948550614546355.

Deci, E. L., Olafsen, A. H., \& Ryan, R. M. (2017). Self-determination theory in work organizations: The state of a science. Annual review of organizational psychology and organizational behavior, 4, 19-43. DOI: 10.1146/annurev-orgpsych-032516-113108

Deci, E. L., La Guardia, J. G., Moller, A. C., Scheiner, M. J., \& Ryan, R. M. (2006). On the benefits of giving as well as receiving autonomy support: Mutuality in close friendships. Personality and social psychology bulletin, 32, 313-327. DOI: $10.1177 / 0146167205282148$

Downie, M., Koestner, R., \& Chua, S. N. (2007). Political support for self-determination, wealth, and national subjective well-being. Motivation and Emotion, 31, 174-181. DOI: $10.1007 / \mathrm{s} 11031-007-9070-0$

Ellis, N. T., \& Jones, C. (2019). Banning ethnic hairstyles "upholds this notion of white supremacy." States pass laws to stop natural hair discrimination. USA Today. https:/www.usatoday.com/story/news/nation/2019/10/14/black-hair-laws-passed-stopnatural-hair-discrimination-across-us/3850402002/ 
Running Head: Collective Autonomy, Power and Status

Eibach, R. P., \& Keegan, T. (2006). Free at last? Social dominance, loss aversion, and White and Black Americans' differing assessments of racial progress. Journal of personality and social psychology, 90, 453-467. DOI: 10.1037/0022-3514.90.3.453

Greenaway, K. H., Cruwys, T., Haslam, S. A., \& Jetten, J. (2016). Social identities promote well-being because they satisfy global psychological needs. European Journal of Social Psychology, 46, 294-307. doi:10.1002/ejsp.2169

Greenaway, K. H., Haslam, S. A., Cruwys, T., Branscombe, N. R., Ysseldyk, R., \& Heldreth, C. (2015). From "we" to "me": Group identification enhances perceived personal control with consequences for health and well-being. Journal of Personality and Social Psychology, 109, 53-74. DOI: 10.1037/pspi0000019

Haslam, A. S., Jetten, J., Postmes, T., \& Haslam, C. (2009). Social identity, health and wellbeing: An emerging agenda for applied psychology. Applied Psychology, 58, 1-23.

Haslam, C., Cruwys, T., \& Haslam, S. A. (2014). "The we's have it": Evidence for the distinctive benefits of group engagement in enhancing cognitive health in aging. Social Science \& Medicine, 120, 57-66.

Helms, J. E. (1995). An update of Helms's White and People of Color racial identity models. In J. G. Ponterotto, J. M. Casas, L. A. Suzuki, \& C. M. Alexander (Eds.), Handbook of multicultural counseling (pp. 181-198). Thousand Oaks, CA: Sage.

Holding, A. C., Barlow, M., Koestner, R., \& Wrosch, C. (2020). Why are we together? A dyadic longitudinal investigation of relationship motivation, goal progress, and adjustment. Journal of personality, 88, 464-477. DOI: 10.1111/jopy.12503

Hornsey, M. J. (2008). Social identity theory and self-categorization theory: A historical review. Social and personality psychology compass, 2, 204-222. 
Running Head: Collective Autonomy, Power and Status

Hirsch, M., Verkuyten, M., \& Yogeeswaran, K. (2019). To accept or not to accept: Level of moral concern impacts on tolerance of Muslim minority practices. British Journal of Social Psychology, 58, 196-210. DOI: 10.1111/bjso.12284

Iyengar, S. S., \& Lepper, M. R. (1999). Rethinking the value of choice: a cultural perspective on intrinsic motivation. Journal of personality and social psychology, 76, 349-366.

Jonas, E., McGregor, I., Klackl, J., Agroskin, D., Fritsche, I., Holbrook, C., ... \& Quirin, M. (2014). Threat and defense: From anxiety to approach. In Advances in experimental social psychology (Vol. 49, pp. 219-286). Academic Press.

Kachanoff, F.J., Caouette, J., \& Wohl, M.J.A., \& Taylor, D.M., (2017). Allowing the victim to draw a line in history: Intergroup apology effectiveness as a function of collective autonomy support. European Journal of Social Psychology. 47, 663-676. DOI: $10.1002 /$ ejsp.2260

Kachanoff, F. J., Cooligan, F., Caouette, J., \& Wohl, M. J. (2020). Free to fly the rainbow flag: the relation between collective autonomy and psychological well-being amongst LGBTQ+ individuals. Self and Identity, 1-33. DOI: 10.1080/15298868.2020.1768890

Kachanoff, F.J., Kteily N., Gray, K., (2021, May). Evaluating impact of anti-racist messages which highlight harm of indifference. Paper presented at Society for the Psychological Study of Social Issues (SPSSI) Virtual Conference.

Kachanoff, F. J., Kteily, N. S., Khullar, T. H., Park, H. J., \& Taylor, D. M. (2020). Determining our destiny: Do restrictions to collective autonomy fuel collective action? Journal of personality and social psychology, 119, 600-632. DOI: 10.1037/pspi0000217

Kachanoff, F. J., Taylor, D. M., Caouette, J., Khullar, T. H., \& Wohl, M. J. A. (2019). 
Running Head: Collective Autonomy, Power and Status

The chains on all my people are the chains on me: Restrictions to collective autonomy undermine the personal autonomy and psychological well-being of group members. Journal of Personality and Social Psychology. DOI: 10.1037/pspp0000177

Kachanoff, F. J., Wohl, M. J., Koestner, R., \& Taylor, D. M. (2020). Them, us, and I: How group contexts influence basic psychological needs. Current Directions in Psychological Science, 29, 47-54. doi: 10.1177/0963721419884318

Holding, A., \& Koestner, R. (2021). Did the Black Lives Matter movement help Black young adults recover from the damaging psychological effects of the COVID-19 pandemic? Invited research report, Quebec English- Speaking Communities Research Network (QUESCREN). https://www.youtube.com/watch?v=3SBddGYonik\&t=1689s

Lammers, J., Stoker, J. I., Rink, F., \& Galinsky, A. D. (2016). To have control over or to be free from others? The desire for power reflects a need for autonomy. Personality and Social Psychology Bulletin, 42, 498-512. DOI: 10.1177/0146167216634064

Legate, N., Ryan, R. M., \& Rogge, R. D. (2017). Daily autonomy support and sexual identity disclosure predicts daily mental and physical health outcomes. Personality and Social Psychology Bulletin, 43, 860-873. DOI: 10.1177/0146167217700399

Legate, N., Ryan, R. M., \& Weinstein, N. (2012). Is coming out always a "Good Thing”? Exploring the relations of autonomy support, outness, and wellness for Lesbian, Gay, and Bisexual individuals. Social Psychological and Personality Science, 3, 145-152. DOI: $10.1177 / 1948550611411929$

Legault, L., Gutsell, J. N., \& Inzlicht, M. (2011). Ironic effects of antiprejudice messages: How motivational interventions can reduce (but also increase) prejudice. Psychological Science, 22, 1472-1477. 
Running Head: Collective Autonomy, Power and Status

Leigh, A., \& Melwani, S. (2019). \#BlackEmployeesMatter: mega-threats, identity fusion, and enacting positive deviance in organizations. Academy of Management Review, 44, 564591. DOI:10.5465/amr.20170127

Luhtanen, R., \& Crocker, J. (1992). A collective self-esteem scale: Self-evaluation of one's social identity. Personality and social psychology bulletin, 18(3), 302-318.

Mageau, G. A., Ranger, F., Joussemet, M., Koestner, R., Moreau, E., \& Forest, J. (2015).

Validation of the perceived parental autonomy support scale (P-PASS). Canadian Journal of Behavioural Science/Revue canadienne des sciences du comportement, 47, 251-262. DOI: 10.1037/a0039325

Magistad, M. K. (2016). Britain's undergoing an identity crisis. Retrieved from https://www.pri.org/stories/2016-10-06/britains-undergoing-identity-crisis

Mandela, N. (1995). Long walk to freedom: The autobiography of Nelson Mandela. Boston: Back Bay Books.

Mummendey, A., Kessler, T., Klink, A., \& Mielke, R. (1999). Strategies to cope with negative social identity: predictions by social identity theory and relative deprivation theory. Journal of Personality and Social Psychology, 76, 229. DOI: 10.1037/00223514.76.2.229

Munzer, S. R. (2015). Secularization, anti-minority sentiment, and cultural norms in the German circumcision controversy. U. Pa. J. Int'1 L., 37, 503-582.

Nichelle, J. (2018, January 16). "I'm is talking right": How the stigma around Black language holds us back from liberation. Blackyouthproject.Com. http://blackyouthproject.com/imtalking-right-stigma-around-black-language-holds-us-back-liberation/

Niemiec, C. P., \& Ryan, R. M. (2009). Autonomy, competence, and relatedness in the classroom: 
Running Head: Collective Autonomy, Power and Status

Applying self-determination theory to educational practice. Theory and research in Education, 7, 133-144. DOI: 10.1177/1477878509104318

Ofosu, E. K., Chambers, M. K., Chen, J. M., \& Hehman, E. (2019). Same-sex marriage Legalization associated with reduced implicit and explicit antigay bias. Proceedings of the National Academy of Sciences, 116, 8846-8851. DOI: 10.1073/pnas.1806000116

O'Neill, D. I. (1999). Multicultural liberals and the Rushdie affair: a critique of Kymlicka, Taylor, and Walzer. The review of politics, 61, 219-250. DOI: $10.1017 / \mathrm{S} 0034670500051986$

Oyserman, D. (2007). Social identity and self-regulation. In A. Kruglanski, \& T. Higgins (Eds.), Social Psychology: Handbook of basic principles (pp. 432-453). New York, NY: Guilford Press.

Parker, P., Ryan, R., Duineveld, J., \& Bradshaw, E. (2019, April 18). Validation of the social identity group need satisfaction and frustration scale. Unpublished Manuscript available at https://doi.org/10.31234/osf.io/ycbwe

Peetz, J., Gunn, G. R., \& Wilson, A. E. (2010). Crimes of the past: Defensive temporal distancing in the face of past in-group wrongdoing. Personality and Social Psychology Bulletin, 36, 598-611. Doi: 10.1177/0146167210364850

Pelletier, L. G., Séguin-Lévesque, C., \& Legault, L. (2002). Pressure from above and pressure from below as determinants of teachers' motivation and teaching behaviors. Journal of Educational Psychology, 94, 186-196. DOI:10.1037//0022-0663.94.1.186

Pratto, F. (2016). On power and empowerment. British Journal of Social Psychology, 55, 1-20. DOI:10.1111/bjso.12135

Race, M. (2021). Cecil Rhodes statue will not be removed by Oxford College. BBC News. 
Running Head: Collective Autonomy, Power and Status

https://www.bbc.com/news/uk-england-oxfordshire-57175057

Ray, V. (2019). A theory of racialized organizations. American Sociological Review, 84, 26-53.

DOI: $10.1177 / 0003122418822335$

Rhodan, M. (2014). U.S military rolls back restrictions on Black hairstyles. Time Magazine. https://time.com/3107647/military-black-hairstyles/

Ryan, R. M., \& Deci, E. L. (2017). Self-Determination Theory: Basic Psychological Needs in Motivation, Development, and Wellness. New York: The Guilford Press.

Ryan, W. S., Hunger, J. M., \& Major, B. (2017). Applying intergroup relations research to understanding LGB health disparities. Journal of Social Issues, 73, 477-492. DOI: 10.1111/josi.12227

Schmitt, M. T., Branscombe, N. R., Postmes, T., \& Garcia, A. (2014). The consequences of perceived discrimination for psychological well-being: A meta-analytic review. Psychological Bulletin, 140, 921-948. DOI: 10.1037/a0035754

Shnabel, N., \& Nadler, A. (2015). The Role of Agency and Morality in Reconciliation Processes: The Perspective of the Needs-Based Model. Current Directions in Psychological Science, 24, 477-483. DOI: 10.1177/0963721415601625

Sidanius, J., Liu, J. H., Shaw, J. S., \& Pratto, F. (1994). Social dominance orientation, hierarchy attenuators and hierarchy enhancers: Social dominance theory and the criminal justice system. Journal of Applied Social Psychology, 24, 338-366. DOI: 10.1111/j.15591816.1994.tb00586.x

SimanTov-Nachlieli, I., Shnabel, N., \& Halabi, S. (2016). The power to be moral: Affirming Israelis' and Palestinians' agency promotes prosocial tendencies across group boundaries. Journal of Social Issues, 72, 566-583. 
Running Head: Collective Autonomy, Power and Status

Stefaniak, A., \& Wohl, M. J. (2021). In time, we will simply disappear: Racial demographic shift undermines privileged group members' support for marginalized social groups via collective angst. Group Processes \& Intergroup Relations, DOi:10.1177/13684302211023551

Stephan, W. G., Ybarra, O., Morrison, K. R. (2009). Intergroup threat theory. In: T. Nelson (Ed.), Handbook of Prejudice (pp.43-59).Mahwah, NJ: Lawrence Erlbaum.

Tajfel, H., \& Turner, J. C. (1979). An integrative theory of intergroup conflict. In W. G. Worchel, \& S. Austin (Eds.), The social psychology of intergroup relations (pp. 33-47). Monterey, CA: Brooks/Cole.

Takahashi, K., \& Jefferson, H. (2021, February 4). When the Powerful Feel Voiceless: White Identity and Feelings of Racial Voicelessness. https://doi.org/10.31234/osf.io/ry97q

Tatum, B. (1992). Talking about race, learning about racism: The application of racial identity development theory in the classroom. Harvard educational review, 62, 1-25. DOI: 10.17763/haer.62.1.146k5v980r703023

The Islamic veil across Europe. (2018). BBC News. https://www.bbc.com/news/world-europe13038095

Timalsina, T. (2021). Why Rhodes must fall. https://harvardpolitics.com/rhodes-must-fall/ Truth and Reconciliation Commission of Canada. (2015). Final Report of the Truth and Reconciliation Commission of Canada: Honouring the Truth, Reconciling for the Future. Summary. Volume One. James Lorimer Limited, Publishers.

Tuck, E., \& Yang, K. W. (2012). Decolonization is not a metaphor. Decolonization: Indigeneity, education \& society, 1, 1-40.

Unzueta, M. M., Lowery, B. S. (2008). Defining racism safely: The role of self-image 
Running Head: Collective Autonomy, Power and Status

maintenance on White Americans' conceptions of racism. Journal of Experimental Social Psychology, 44,1491-1497. DOI: 10.1016/j.jesp.2008.07.011

Van Zomeren, M., Leach, C. W., Spears, R. (2012). Protesters as "passionate economists": A dynamic dual pathway model of approach coping with collective disadvantage. Personality and Social Psychology Review, 16, 180-199. DOI:

$10.1177 / 1088868311430835$

Van Zomeren, M., Postmes, T., \& Spears, R. (2008). Toward an integrative social identity model of collective action: A quantitative research synthesis of three socio-psychological perspectives. Psychological Bulletin, 134, 504-535.DOI: 10.1037/0033-2909.134.4.504

Verkuyten, M., Adelman, L., \& Yogeeswaran, K. (2020). The Psychology of intolerance: Unpacking diverse understandings of intolerance. Current Directions in Psychological Science, 29, 467-472. DOI: 10.1177/0963721420924763

Verkuyten, M., Adelman, L., \& Yogeeswaran, K. (2021). Tolerance as forbearance: Overcoming intuitive versus deliberative objections to cultural, religious, and ideological differences. Psychological Review. DOI: 10.1037/rev0000228

Verkuyten, M., Yogeeswaran, K., \& Adelman, L. (2020). The negative implications of being tolerated: Tolerance from the target's perspective. Perspectives on Psychological Science, 15, 544-561. DOI: 10.1177/1745691619897974

Walker, I., Smith, H. J. (2002). Relative deprivation: Specification, development, and integration. Cambridge: Cambridge University Press.

Williams, G. C., Lynch, M. F., McGregor, H. A., Ryan, R. M., Sharp, D., \& Deci, E. L. (2006). Validation of the" Important Other" Climate Questionnaire: Assessing Autonomy Support for Health-Related Change. Families, Systems, \& Health, 24, 179-194. DOI: 
Running Head: Collective Autonomy, Power and Status

$10.1037 / 1091-7527.24 .2 .179$

Zárate, M. A., Shaw, M., Marquez, J. A., \& Biagas Jr, D. (2012). Cultural inertia: The effects of cultural change on intergroup relations and the self-concept. Journal of Experimental Social Psychology, 48, 634-645. DOI: 10.1016/j.jesp.2011.12.014 